\title{
Alternative mental health therapies in prolonged lockdowns: narratives from Covid-19
}

\author{
Petar Radanliev ${ }^{1}$ (D) . David De Roure ${ }^{1}$
}

Received: 3 June 2021 / Accepted: 28 July 2021 / Published online: 7 August 2021

(c) The Author(s) 2021

\begin{abstract}
Identify and review alternative (home-based) therapies for prolonged lockdowns. Interdisciplinary study using multi-method approach - case study, action research, grounded theory. Only secondary data has been used in this study. Epistemological framework based on a set of digital humanities tools. The set of tools are based on publicly available, open access technological solutions, enabling generalisability of the findings. Alternative therapies can be integrated in healthcare systems as home-based solutions operating on low-cost technologies.
\end{abstract}

Keywords Alternative therapies $\cdot$ Art Therapy $\cdot$ Disease X · Covid-19

\section{Introduction}

Covid-19 has challenged the perception that humans are 'autonomous and in control' and exposed human vulnerabilities that threaten our social existence [1]. This article conducts

Clinical Impact Statement: Covid-19 has triggered a significant effect on our mental health, with a wide expectation among medical practitioners of emerging mental health crisis triggered by the prolonged lockdown. This article reviews 11 alternative (home-based) mental health therapies, based on arts and humanities and new (low-cost) mobile technologies. The main findings of this article are presented as a new framework enhanced with a set of 11 tools based on alternative (home-based) mental health therapies. The data reported in this manuscript were obtained from publicly available data from: (1) The Patient Voices digital stories; (2) Silence Speaks; (3) The Voice Library; (4) Cognitive Dynamics - bringing Art to Life; (5) online forums and blog posts; (6) Google Trends data; (7) consumer report data; (8) social media. A bibliography of journal articles, working papers, conference presentations is available om the list of references included in the article. The variables and relationships examined in the present article have not been examined in any previous or current articles, or to the best of our knowledge in any papers that will be under review soon.

This article is part of the COVID-19 Health Technology: Design, Regulation, Management, Assessment

Petar Radanliev

petar.radanliev@eng.ox.ac.uk

1 Department of Engineering Sciences, University of Oxford, Oxford OX1 3QG, England, UK an interdisciplinary study using multi-method approach (described further in Fig. 1) and data from Covid-19 to increase our preparedness for Disease X. Disease X is a term adopted by the World Health Organisation WHO where X stands for unexpected-and represents a hypothetical and unknown deadly and fast spreading pathogen. Disease $\mathrm{X}$ is simply a placeholder name, designed to promote research on classes of viruses and not on individual strains, with the aim of improving our preparedness to manage unforeseen pathogens. The term was coined in 2018, therefore Covid-19 can be considered as the first strain of Disease X. This project, however, refers to Disease $\mathrm{X}$ as the next-new and future pathogen.

The intent is to study extensively the case of Covid-19 and improve our preparedness for the next deadly and global pandemic. The next Disease $X$ event can be as contagious as Covid-19 and deadly as Ebola (50-90\% fatality) and could cause a pandemic similar to the filovirus that causes Ebola, it could be a virus that we already know, like the Nipah virus, it could be a completely new virus, or a frequent pathogen like the influenza virus. Disease X could be passed on from animals to humans, such as yellow fever, rabies, brucellosis, Lyme disease, or HIV, and could be even worse than Covid-19. The rising number of novel viruses is to a big extent caused by wildlife trade and ecological destruction of natural habitats, which cause the extinction of the larger predator animals, leaving small animals, like rats, bats and insects. Since the small animals can survive living with humans, when we change the ecology, they leave and move to urban areas. They can easily spread viruses in areas with 
Fig. 1 Research methodologyepistemological approach for studying Disease X events

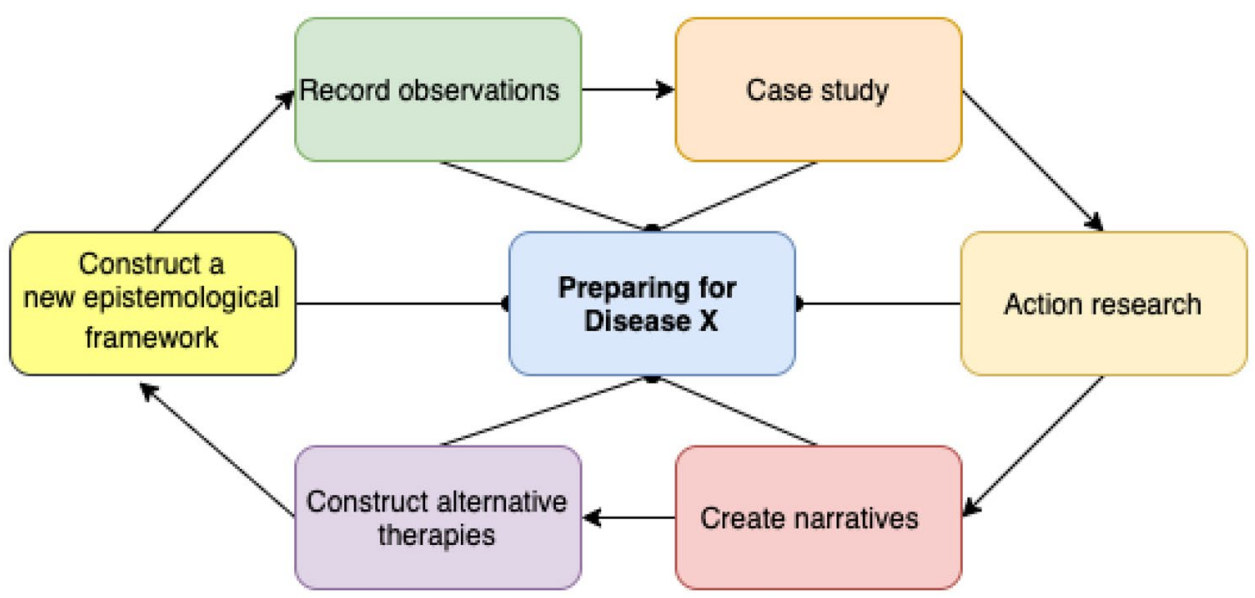

low hygiene and high population density, which presents favourable conditions for viruses. Eventually some of these viruses reach a global hub (e.g., Wuhan).

Disease X can happen anytime, and we are not more prepared than we were for Covid-19, which will be remembered by politically motivated and uncoordinated responses. To prepare for Disease X, national healthcare policies need to support the adaptation of new technologies in healthcare systems to maximise the benefit from new digital solutions for pandemic management. Many developed countries-driven by Covid-19- have created national programs and initiatives enabling their healthcare systems to benefit from the increased digitalisation for pandemic management. But the adoption of new technologies is mirrored with an increased concern on the emerging risks from integrating such technologies in critical infrastructure - e.g., healthcare systems. These concerns are mostly related to security, privacy and trust, and can result with a lower rate of adoption. In addition, the less developed regions (e.g., Africa) have not been able to respond as fast to the Covid-19 challenges and are not getting the best benefit from new digital solutions.

\subsection{How can we adapt to future global pandemics?}

The aim of this paper is to address existential questions emerging from the Covid-19 pandemic. The first question we ask is how can we adapt to future global pandemics? The Covid-19 pandemic has triggered an irreversible chain of events, reflecting new behaviours and changes in the way we do things. Some of these changes would have been impossible to imagine before Covid-19. Changes in handshakes, changing from fact-to-face and into online study, working from home, paying people to stay at home, among many other changes. This has resulted in a reality that is far different than just few months ago, and the world hasn't adapted to this change, yet. We are currently experiencing a form of 'state capitalism', when the state authorises a substantial
Keynesian stimulus by extending credit and making direct payments to businesses. Salary payments are calculated on the basis of the employee earlier creation of value in the market, rather than their current value or usefulness of their work. With the relatively short period of the Covid-19 pandemic, this has kept the markets operational. In a prolonged pandemic, state would have to take more radical actions, and in such prolonged widespread illness, the extra funds for people and hospitals would be much harder to sustain. Eventually, the system would need to return to normal, which would require further austerity, limiting the ability to respond to future pandemics. Such scenario leads only to a failed state and collapsed community and welfare system. The alternative is to continue with a form of state socialism, when the state continues to provide payments and protect markets to counter the effect of a prolonged pandemic. This also leads to economic recession and in a long run, failed state, collapsed community and welfare system. Because of these unattractive scenarios, we need to re-examine our perception of value as a subset of economics. This means that we need to examine the value of other aspects of value in our society (e.g., arts and humanities) and the values of alternative (i.e., home based) therapies for our mental wellbeing during prolonged lockdowns, in our efforts to building a more resilient society and economy. This presents a radically different approach to our perception of value and goes far beyond the traditional understanding of economic value in physical and mental healthcare.

\subsection{Why are we not prepared for Covid-19 and Disease $X$ ?}

The world has faced many pandemics in the past, ${ }^{1}$ but Covid-19 has demonstrated that we remain unprepared.

$\overline{{ }^{1} \text { https://en.wikipedia.org/wiki/Pandemic }}$ 
Research funding on the topic of global pandemics has historically been very limited and this is noticeable in the historical research output. A Web of Science search on the word 'global pandemics' resulted with just over 9,800 records (data from years 1900-2021). When I compare this with 397,074 records on business, 474,774 on fishing, 807,000 on 'marketing', then the lack of research problem becomes obvious. Research records on global pandemics have more than tripled since the rise of Covid-19, in a recent study published just after the first wave, the same Web of Science search on the word 'global pandemics' resulted with 3708 [2] (data from years 1900-2020). But this is hardly comparable to some of the data I found on other scientific records. While performing a very different search, we found 4,399 records on the topic of 'Brexit' - a term that was coined during a referendum in 2016. In other words, more research has been funded on Brexit (from years 2016-2021), than on global pandemics (data from years 1900-2020). This shows how desperately we need to re-examine our perception of value of research (on global pandemics). The underlaying cause for our unpreparedness for Covid-19 was the lack of funding (research), followed by the complexity of predicting which pathogen will be the cause of the pandemic and the complexity in observing, modelling and controlling the phenomenon.

\subsection{How can we adapt in anticipation of Disease X?}

The first topic analysed in this study is related to adapting to pandemics and discoursing how qualitative methods can be applied to observe in what way different people adapted to Covid-19 and to capture digital narratives related to values from arts and humanities as alternative therapies for physical and mental health. In terms of relating values to economics, one of the hardest hit sectors during Covid-19 are directly related to arts and humanities (e.g., the creative industries, theatres, cinemas, visual and studio arts, performing arts). At the same time, these sectors have provided some of the crucial mental health support. To identify the real value of these sectors, a new epistemological approach (Fig. 1) is developed in this article, with unique tools to analyse the value of alternative therapies during Covid-19.

Recent studies on this topic discovered that 'female healthcare workers are more vulnerable to mental health problems' and that 'timely and special care' is required during such events [3]. Another recent study conducted a systematic review on what interventions are needed to address mental health issues in healthcare workers during infectious disease outbreaks [4]. The study grouped interventions into four categories: 1) informational support; 2) instrumental support; 3) organisational support; and 4) emotional and psychological support - in other words 'psychoeducation and training, mental health support team, peer-support and counselling, therapy, digital platforms and tele-support'. Avoiding these requirements for timely and special care requirements, can result with a range of negative mental health effects. Although these effects need to be studied in much greater detail, recent studies are already investigating the links and the "causal influences of neuroticism on mental health and cardiovascular disease' [5]. Other studies investigate the Covid-19 related mental health issues in college students [6]. Reports on other fields e.g., STEM advise that 'a change in policies of organizations.. may be required to provide accommodation and compensation to minimize the negative impact on the professional status and career of men and women who work in STEM fields [7]. The research methodology in Fig. 1 building upon recommendations from recent studies that argue for using digital solutions in healthcare for online cognitive behavioural therapies and counselling services and mental care provision, while cautioning about the potential cyber risks [8]. A qualitative case study and ethnographic approach is used, to seek narratives to challenge our understanding of value. The aim of this article is to progress towards increased preparedness and increased understanding of managing global pandemics with emerging technologies. In particular, the study objectives are to identify alternative (home-based) therapies for prolonged lockdowns and record as much data on the values of arts and humanities in the Covid-19 pandemic, and apply multimethod research to use the data for increased preparedness for Disease X. As we have seen from Covid-19, the world needs to increase in efforts towards achieving a better control of managing fast spreading deadly pandemics.

This study integrates the distant fields of healthcare and arts and humanities. The research methodology applied grounded theory and was designed with an iterative methodology. Lessons learned from each iteration are used in the design and control of the next iteration cycle. To reduce and overcome the complexity of the iterative methodological process, and to progress towards a better understanding of the outcome of each iteration, a variety of complimentary but different techniques are used e.g., case study, action research. The complementary approach provided insights on the Disease $\mathrm{X}$ phenomenon at different lengths and time scales.

\section{How can we prepare for Disease X?}

The first approach for preparing for a global disease analysed in this article is related to applying new technologies for managing the negative effects on healthcare systems and people's mental health of prolonged lockdowns. This part of the study applies grounded theory with qualtitative case study research, to construct digital narratives related to physical and mental health during prolonged lockdowns, 
Fig. 2 Alternative mental therapies for prolonged lockdowns

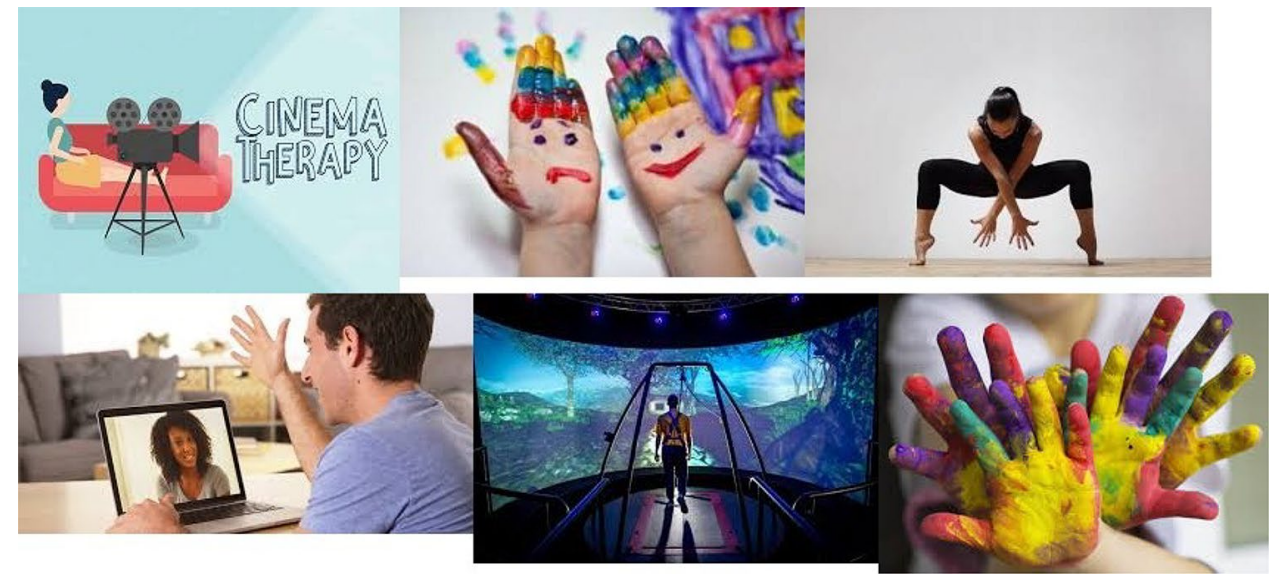

including home educational strategies and coping mechanisms, and to investigate alternative home-based mental health therapies. The aim is to devise alternative mental health solutions to prepare for prolonged social isolation caused by global pandemics. The analysis in this part of the research is based on recording observations on how humans around the world adapted to the Covid-19 pandemic. Through experimental observations the study progressively captures the complexity of adapting to global pandemics, while taking into consideration a number of parameters related to physical and mental health. The experimental observations cycle is reflexed in the first postulate $P_{1}$ : we can adapt to global pandemics.

During the catastrophic social changes caused by Covid19 , one of the hardest hit sectors in the first and the second wave are the creative industries, theatres, cinemas, and many other areas that belong to the arts and humanities sectors, such as visual and studio arts, performing arts. At the same time, these sectors have provided much of the essential mental health support. For example, most people coped with the Covid-19 lockdown by turning to Netflix and other home-based visual entertainment, mostly produced by performing artists in visual studios. In addition, arts and crafts were used as an educational strategy and coping mechanisms by parents during the lockdown [9]. Art therapy was found helpful with finding control in the Covid-19 chaotic times [10]. This defines the rationale for the first objective $(\mathrm{O})_{1}$ of this article - which is to construct a new epistemological approach (i.e., method) for recording the real value of arts and humanities during Covid-19.

\section{Eistemological model for recording knowledge on preparing for Disease $X$}

A combined case study, grounded theory, and action research methodology was the method of choice used to create digital narratives as a form of digital storytelling. The aim was to digitalise stories and to create a permanent records from everyday aspects of people life's during Covid-19, presenting narratives as stories of values (and the struggles) in difficult times. The objective was to construct narratives of different methods $(\mathrm{M})$ centred on arts and humanities as alternative therapy (Fig. 2) during prolonged lockdowns. The methods analysed include $\mathbf{M}_{1}$ : cinema therapy [11]; $\mathbf{M}_{2}$ : film/video-based therapy $[12,13] ; \mathrm{M}_{3}$ : therapeutic filmmaking [14]; $\mathbf{M}_{4}$ : Virtual Reality [15]; $\mathbf{M}_{5}$ : video art (remix) therapy [16]; $\mathrm{M}_{6}$ : psychotherapy [17-19]; $\mathrm{M}_{7}$ : expressive arts therapy [20]; and $\mathbf{M}_{8}$ : creative arts therapies (art therapy) [21, 22]; $\mathbf{M}_{9}$ dance/movement therapy [23-25]; $\mathbf{M}_{10}$ drama therapy [26, 27]; music therapy [28]; $\mathbf{M}_{11}$ : poetry therapy [29-31], and psychodrama [32].

Some of the data sources (for the case study-action research) on how these methods are applied during Covid19 included: (1) The Patient Voices digital stories; (2) Silence Speaks; (3) The Voice Library; (4) Cognitive Dynamics - bringing Art to Life; (5) online forums and blog posts; (6) Google Trends data; (7) consumer report data; (8) social media. The experimental developments emerging from the digital narratives is centred of specific dissemination approach (Table 1) found in different sources and used for constructing a particular point of view e.g. narratives of struggle, courage and transformation. There are however concerns in recent studies on the increased recreational use of virtual reality and the impact on physical and mental wellbeing during the Covid-19 lockdown [33]. This can be a concern, especially for vulnerable individuals. This was one of the reasons why this study applied the case study-action research, which facilitated observing and analysing the application of methods in different data sources and recording narratives on Covid-19 (collaborative action research). The case study - grounded theory research enabled creating narratives and complimented the analysed methods with a new set of epistemological tools (Et). The new set of tools provides a structure on how different methods (e.g., research films recordings) can become socially interactive, by being 
Table 1 Conceptual epistemological framework emerging from digital narratives on arts and humanities as therapies during global pandemics

\begin{tabular}{|c|c|c|c|}
\hline ED & Exploitation (E) and dissemination $\left(\mathrm{D}_{\mathrm{i}}\right)$ of healthcare narratives to different audiences (collected during Covid-19) & Et & $\mathrm{M}$ \\
\hline $\mathrm{D}_{\mathrm{i} 1}$ & YouTube videos for global reach of personal narratives during Covid-19 e.g., the case of cinema therapy ${ }^{2}$ & $\mathrm{Et}_{1}$ & $\mathrm{M}_{1}$ \\
\hline $\mathrm{D}_{\mathrm{i} 2}$ & $\begin{array}{l}\text { Embedded video recordings on selected webpages for targeted reach of personal narratives during Covid-19 e.g., film/video- } \\
\text { based therapy }\end{array}$ & $\mathrm{Et}_{2}$ & $\mathrm{M}_{2}$ \\
\hline $\mathrm{E}_{1}$ & $\begin{array}{l}\text { Viddler community building through therapeutic filmmaking during Covid-19 for informing, interacting and engaging with } \\
\text { local communities }\end{array}$ & $\mathrm{Et}_{3}$ & $\mathrm{M}_{3}$ \\
\hline $\mathrm{E}_{2}$ & $\begin{array}{l}\text { Virtual reality of 3D shaped Covid-19 narratives with SecondLife for Education-for safe and secure real-time collaboration } \\
\text { and virtual learning in a global community }\end{array}$ & $\mathrm{Et}_{4}$ & $\mathrm{M}_{4}$ \\
\hline $\mathrm{D}_{\mathrm{i} 3}$ & $\begin{array}{l}\text { Blogger to publish narratives from video art (remix) therapy during Covid-19 and to encourage a discussion on their therapeuti- } \\
\text { cal values }\end{array}$ & $\mathrm{Et}_{5}$ & $\mathrm{M}_{5}$ \\
\hline $\mathrm{E}_{3}$ & $\begin{array}{l}\text { Storytelling with digital humanities tools: Omeka sharing digital collections and creating media-rich online exhibits, with com- } \\
\text { plex narratives that allow users to tag favourites and measure the value of psychotherapy }\end{array}$ & $\begin{array}{ll}\mathrm{Et}_{6} \\
\mathrm{Et}_{1}\end{array}$ & $\mathrm{M}_{6}$ \\
\hline $\mathrm{E}_{4}$ & $\begin{array}{l}\text { Data visualisation with digital humanities tools Gephi, and Voyant to present data visualisations of narratives on expressive arts } \\
\text { therapy }\end{array}$ & $\mathrm{Et}_{7}$ & $\mathrm{M}_{7}$ \\
\hline$D_{i 4}$ & $\begin{array}{l}\text { Piktochart for creating engaging content in different formats and translating complex data into a visual story with digital } \\
\text { humanities tools on narratives of creative arts therapies (art therapy) }\end{array}$ & $\mathrm{Et}_{8}$ & $\mathrm{M}_{8}$ \\
\hline$E_{5}$ & $\begin{array}{l}\text { WeVideo for video creation and editing with digital humanities tools to inspire meaningful example-based learning on the topic } \\
\text { of dance/movement therapy }\end{array}$ & $\mathrm{Et}_{9}$ & $\mathrm{M}_{9}$ \\
\hline $\mathrm{E}_{6}$ & $\begin{array}{l}\text { TikTok for online presence in new and emerging media-short } 60 \mathrm{~s} \text { videos; followed with poster papers in } Q Q, \text { WeChat, } \\
\text { and Printterest; reshared as news in Reddit, and run as verbatim with text on Tumblr, and Medium,- on the topic of drama } \\
\text { therapy, music therapy }\end{array}$ & $\mathrm{Et}_{10}$ & $\mathrm{M}_{10}$ \\
\hline$D_{i 5}$ & $\begin{array}{l}\text { Scribd, SlideShare, SlideRocket, authorSTREAM, present.me, and other less know platforms e.g., Zooniverse, Web Observatory } \\
\text { for sharing of narratives on the topics of poetry therapy, and psychodrama }\end{array}$ & $\mathrm{Et}_{11}$ & $\mathrm{M}_{11}$ \\
\hline
\end{tabular}

${ }^{2}$ https://www.youtube.com/channel/UCCYX4s1DCn51Hpf1peHS30Q

published online in open access for public dissemination, promoting and provoking interest for further exploitation (i.e., applying) of these methods during a Disease $\mathrm{X}$ event. The new set of epistemological tools (Et) was developed based on the value measured from each therapy during Covid-19 (i.e., popularity, acceptance, usability). The set of epistemological (i.e., digital humanities) tools (Et) and the values is enhanced with a conceptual epistemological framework (Ef), developed specifically to emphasise the values of different therapies - in a specific case scenario (e.g., global reach, targeted reach).

The epistemological framework undertakes experimental developments in researching the: (a) need to integrate digital narratives of different arts and humanities therapies with the digital humanities tools (listed in Table 1); (b) need to integrate arts and humanities therapies and existing reciprocities on digital narratives. The expected difficulties include the difference in duration of Disease $\mathrm{X}$ and the timeline of Covid-19 - presenting a different set of difficulties, e.g., disabling action research and the ability to participate and influence the outcomes. Alternatives to mitigate this risk include observing narratives from past events (recorded online) and suggesting potential alternative therapies as solutions during a Disease $\mathrm{X}$ event. This means that the case study - action research will change at some point during the therapy - from active engagement, to passive observation i.e., grounded theory.

\section{Conclusion}

This study developed solutions for alternative therapies that can be applied with low-cost mobile devices for managing metal health during a Disease $\mathrm{X}$ event-while preserving the patients security, privacy and trust. The article presented a conceptual epistemological framework based on digital humanities tools that can be used for alternative therapies during prolonged lockdowns. The epistemological framework is designed through studying narratives and applying grounded theory, case study and action research on qualitative data samples from Covid-19. The expectation is that the epistemological framework will assist developing countries in harnessing the value of new technological solutions. The framework can be applied in anticipation of a Disease X event, to manage and enable the creation of national initiatives for integrating alternative therapies in healthcare systems, as solutions operating on low-cost technologies.

\subsection{Limitations and future directions}

Although the solutions are aimed at developing and developed countries, the development and validation of the solutions was primarily be applied in developed countries-using the existing knowledge and secondary data on digital healthcare systems. This was grounded on the secondary data availability, which was found mostly from technologically advanced 
healthcare systems i.e., in developed countries. The technological solutions and initiatives for alternative therapies developed in this project need to be supported with testbeds, which can be costly to build and developed countries are faced with financial constraints. The study identified some of the most suitable world leading testbeds (i.e., UK digital catapults), and real-world digital healthcare projects (Table 1) that could be used for testing and validating the new alternative therapies - after the current lockdown restrictions have ended. Alternative (i.e., suitable and similar) digital testbeds exist and are operational in the EU, UK and USA, and shortage of testbeds is not expected to be a concern. By developing and testing the solutions in state of the art testbeds, the framework will maximise the value for developed countries and enable developing countries to benefit from tested and verified digital solutions for Disease X management.

Acknowledgements Eternal gratitude to the Fulbright Visiting Scholar Project.

Authors' contributions (CRediT) Dr Petar Radanliev: Conceptualization, Data curation, Formal analysis, Investigation, Methodology, Visualization, Writing — original draft and review \& editing. Prof. David De Roure: Funding acquisition, Methodology, Project administration, Resources, Software, Supervision, Validation, Writing—review \& editing.

Funding sources This work was supported by the UK EPSRC [grant number: EP/S035362/1] and by the Cisco Research Centre [grant number CG1525381]

Availability of data and materials All data and materials included in the article.

\section{Declarations}

Conflict of Interest On behalf of all authors, the corresponding author states that there is no conflict of interest.

Open Access This article is licensed under a Creative Commons Attribution 4.0 International License, which permits use, sharing, adaptation, distribution and reproduction in any medium or format, as long as you give appropriate credit to the original author(s) and the source, provide a link to the Creative Commons licence, and indicate if changes were made. The images or other third party material in this article are included in the article's Creative Commons licence, unless indicated otherwise in a credit line to the material. If material is not included in the article's Creative Commons licence and your intended use is not permitted by statutory regulation or exceeds the permitted use, you will need to obtain permission directly from the copyright holder. To view a copy of this licence, visit http://creativecommons.org/licenses/by/4.0/.

\section{References}

1. Ten Have H, Gordijn B. Vulnerability in light of the COVID-19 crisis. Med Health Care Philos. 2021;1-2.

2. Radanliev P, De Roure D, Walton R, Van Kleek M, Montalvo, RM, Santos O, Maddox La'Treall T, Cannady S. COVID-19 what have we learned? The rise of social machines and connected devices in pandemic management following the concepts of predictive, preventive and personalized medicine. EPMA J. 2020;11(3):311-32.

3. Liu S, Yang L, Zhang C, Xu Y, Cai L, Ma S, Wang Y, Li, R. Gender differences in mental health problems of healthcare workers during the coronavirus disease 2019 outbreak. J Psychiatr Res. 2021;137:393-400.

4. Zaçe D, Hoxhaj I, Orfino A, Viteritti AM, Janiri L, Di Pietro ML. Interventions to address mental health issues in healthcare workers during infectious disease outbreaks: a systematic review. J Psychiatr Res. 2021;136(April 2021):319-33.

5. Zhang F, Baranova A, Zhou C, Cao H, Chen J, Zhang X, Xu M. Causal influences of neuroticism on mental health and cardiovascular disease. Hum Genet. 2021;1-15.

6. Han Z, Tang X, Li X, Shen Y, Li L, Wang J, Chen X, Hu Z. COVID-19-Related Stressors and Mental Health Among Chinese College Students: A Moderated Mediation Model. Front Public Heal. 2021;9:803.

7. Frize M, Lhotska L, Marcu LG, Stoeva M, Barabino G, Ibrahim F, Lim S, Bezak E. The impact of COVID-19 pandemic on gender-related work from home in STEM fields-Report of the WiMPBME Task Group, Gender, Work Organ. Apr. 2021.

8. Kaiser FK, Wiens M, Schultmann F. Use of digital healthcare solutions for care delivery during a pandemic-chances and (cyber) risks referring to the example of the COVID-19 pandemic. Heal Technol. 2021;1-13.

9. Choi M, Tessler H, Kao G. Arts and crafts as an educational strategy and coping mechanism for Republic of Korea and United States parents during the COVID-19 pandemic. Int Rev Educ. 2020;1-21.

10. Braus M, Morton B. Art Therapy in the Time of COVID-19. Psychol Trauma Theory: Res Pract Policy. 2020;12(S1):S267.

11. Geller JD. Introduction: Psychotherapy through the lens of cinema. J Clin Psychol. 2020;76(8):1423-37.

12. Simpson S, Richardson L, Pietrabissa G, Castelnuovo G, Reid C. Videotherapy and therapeutic alliance in the age of COVID-19. Clin Psychol Psychother. 2020.

13. Aafjes-van Doorn K, Békés V, Prout TA. Grappling with our therapeutic relationship and professional self-doubt during COVID-19: Will we use video therapy again?. Couns Psychol Q. 2020;1-12.

14. García-Periago R. Mickey B/Macbeth: Bringing Shakespeare to Prisons and Academia via Film Adaptation. 2020.

15. Singh RP, Javaid M, Kataria R, Tyagi M, Haleem A, Suman R. Significant applications of virtual reality for COVID-19 pandemic. Diabetes Metab Syndr Clin Res Rev. 2020;14(4):661-4.

16. Reid A, Miño P. When Therapy Goes Public: Copyright Gatekeepers and Sharing Therapeutic Artifacts on Social Media. Int J Commun. 2021;15:950-69.

17. Vostanis P, Bell CA. Counselling and psychotherapy postCOVID-19. Couns Psychother Res. 2020;20(3):389-93.

18. Probst T, Stippl P, Pieh C. Changes in provision of psychotherapy in the early weeks of the COVID-19 lockdown in Austria. Int J Environ Res Public Health. 2020;17(11):3815.

19. Humer E, Pieh C, Kuska M, Barke A, Doering BK, Gossmann K, Trnka R, Tavel P. Provision of psychotherapy during the covid-19 pandemic among Czech, German and Slovak psychotherapists. Int J Environ Res Public Health. 2020;17(13):4811.

20. Lau GCY. Coronavirus as a Rite Of Passage: Finding Cures for 'Colonialvirus' in Expressive Arts-Based Research. Ecopoiesis eco-human theory Pract. 2020;1(2).

21. Reed K, Cochran KL, Edelblute A, Manzanares D, Sinn H, Henry M, Moss M. Creative arts therapy as a potential intervention to prevent burnout and build resilience in health care professionals. AACN Adv Crit Care. 2020;31(2):179-90. 
22. Potash JS, Kalmanowitz D, Fung I, Anand SA, Miller GM. Art therapy in pandemics: Lessons for COVID-19. Art Ther. 2020;37(2):105-107.

23. Shuper Engelhard E, Yael Furlager A. Remaining held: dance/ movement therapy with children during lockdown. Body Mov Dance Psychother. 2021;16(1):73-86.

24. Re M. Isolated systems towards a dancing constellation: coping with the Covid-19 lockdown through a pilot dance movement therapy tele-intervention. Body Mov Dance Psychother. 2021;16(1):9-18.

25. Lotan Mesika S, Wengrower $\mathrm{H}$, Maoz H. Waking up the bear: dance/movement therapy group model with depressed adult patients during Covid-19 2020. Body Mov Dance Psychother. 2021;16(1):32-46.

26. Sajnani N. Digital interventions in drama therapy offer a virtual playspace but also raise concern. Drama Ther Rev. 2020;6(1):3-6.

27. Wood LL, White S, Gervais D, Owen M, Moore S, Boylan Z, Cosby O, Ciempa T. Challenges and strategies delivering group drama therapy via telemental health: Action research using inductive thematic analysis. Drama Ther Rev. 2020;6(2):149-65.
28. Mastnak W. Psychopathological problems related to the COVID19 pandemic and possible prevention with music therapy. Acta Paediatr. 2020;109(8):1516-8.

29. Sorensen S, Dubrasky D, Corser GC. Implementing the training program of inter-professional poetry therapy groups in rural communities. Soc Work Groups. 2021;1-10.

30. Sharma D. Reading and rewriting poetry on life to survive the COVID-19 pandemic. J Poet Ther. 2021;1-14.

31. Acim R. Lockdown poetry, healing and the COVID-19 pandemic. J Poet Ther. 2021;1-10.

32. Drakulić AM, Radman V. Crisis psychodrama in the era of COVID-19. Psychiatr Danub. 2020;32(1):22-4.

33. Siani A, Marley SA. Impact of the recreational use of virtual reality on physical and mental wellbeing during the Covid-19 lockdown. Heal Technol. 2021;11(2):425-35.

Publisher's Note Springer Nature remains neutral with regard to jurisdictional claims in published maps and institutional affiliations. 